\title{
Correction to: Evolution of PVA gels prepared without crosslinking agents as a cell adhesive surface
}

\author{
Siddhi Gupta ${ }^{1} \cdot$ Thomas J. Webster $^{2} \cdot$ Arvind Sinha $^{1}$ \\ Published online: 21 July 2020 \\ (c) Springer Science+Business Media, LLC, part of Springer Nature 2020
}

\section{Correction to: Journal of Materials Science: Materials in Medicine (2011) 22:1763-1772 \\ https://doi.org/10.1007/s10856-011-4343-2}

Following the publication of the original article [1], the authors reported an error in Fig. 6a. The image from Fig. 7 depicting the control sample was unintentionally used in place of the image depicting the $14 \%$ hydrogel sample. As such, the image has been replaced as shown below. In addition, the authors would like to update the $2^{\text {nd }}$ sentence of section 3.1.4, which read "These are representative of what is seen for all regions on the gels". To "These are representative of what is seen for all regions on the coverslips". The purpose of this update is to better clarify what is being depicted. The authors would like to emphasize that these two corrections do not in any way alter the results of the article.

The corrected image for Lens Epithelial Cells (shown on right) attached on control (glass coverslips) for Fig. 6a is given below:

Fig. 6

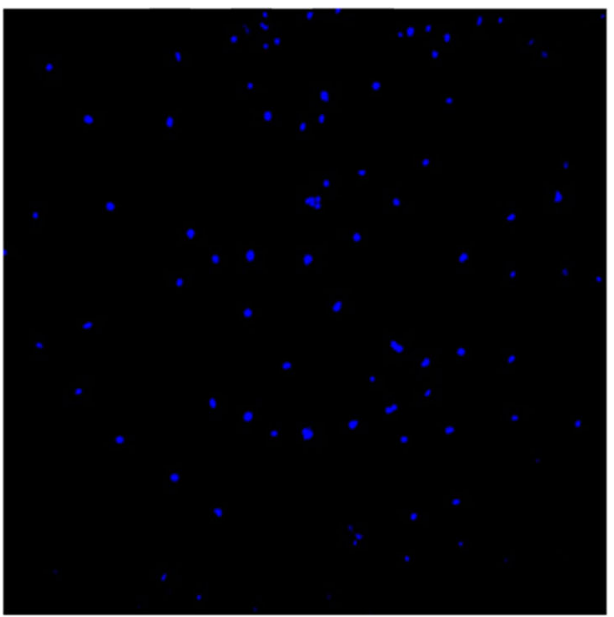

Human Dermal Fibroblasts

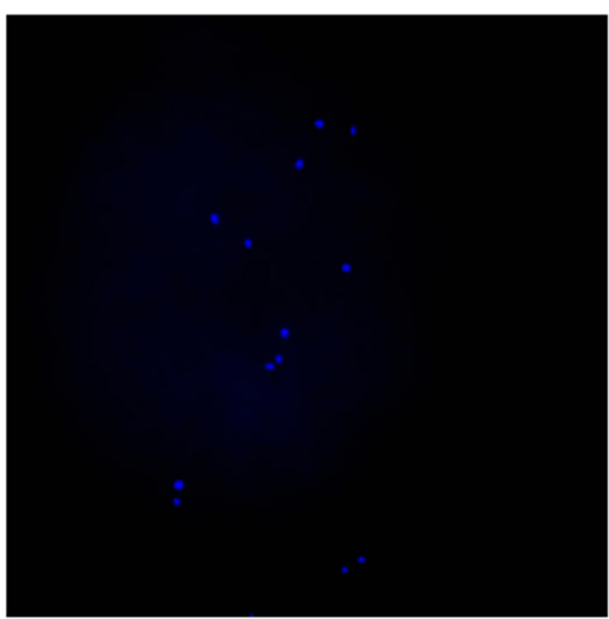

Human Lens Epithelial Cells
The original article can be found online at https://doi.org/10.1007/ s10856-011-4343-2.

Siddhi Gupta

siddhigupta@nmlindia.org

1 CSIR-National Metallurgical Laboratory, Council of Scientific and Industrial Research, Jamshedpur, India

2 School of Engineering and Department of Orthopaedics, Brown University, Providence, RI, USA

\section{Reference}

1. Gupta S, Webster TJ, Sinha A. Evolution of PVA gels prepared without crosslinking agents as a cell adhesive surface. J Mater Sci: Mater Med. 2011;22:1763-72. https://doi.org/10.1007/s10856-0114343-2. 